\title{
Lexicologie als universitaire vakopleiding
}

\author{
W. Martin, Vrije Universiteit Amsterdam, \\ Nederland
}

Abstract: Lexicology as University Vocational Training. This article consists of two parts. Part one (paragraphs 1-3) deals with the notion 'lexicon', part two (paragraphs 4-7) introduces and presents the study programme 'Lexicology' such as it is conceived at the Free University of Amsterdam.

The lexicon as object of study is taken up as 'an organized lexical knowledge bank that language users have at their disposal and which enables them to produce and understand language (at lexical level)'. The main concern of lexicology therefore is the organization and structure of such a bank. The role played by it in both language production and language understanding is illustrated.

In the part dealing with the study programme 'Lexicology' itself most attention is paid to the final attainment levels. A distinction is made between common-general and more specific ones. As to the common-general ones the notion 'lexical knowledge' plays a central role. The various ways of its definition, representation, derivation, exploitation and application are all to be considered. As to the more specific attainment levels a differentiation is made according to 'study-paths', viz.

$$
\begin{aligned}
& \text { - lexicography } \\
& \text { - terminology / terminography } \\
& \text { - and computational lexicology }
\end{aligned}
$$

For all three of them, a short characterization in terms of motivation, aim, final attainment levels and job opportunities is given.

Finally a survey is given of the actual study programme (including the one for the European Lexicography Diploma) so to make clear the relationship between theory and practice and to clarify the notion 'professional training at university level'.

Keywords: COMPUTATIONAL LEXICOLOGIST, EUROPEAN DIPLOMA IN LEXICOGRAPHY, LEXICAL KNOWLEDGE BANK, LEXICAL KNOWLEDGE, LEXICOGRAPHER, LEXICOGRAPHY, LEXICOLOGIST, LEXICOLOGY, LEXICCON, TERMINOLOGIST, TERMINOLOGY

Samenvatting: Dit artikel bestaat uit twee delen. In het eerste deel (par. 1-3) wordt ingegaan op het begrip 'lexicon'. In het tweede gedeelte (par. 4-7) wordt de opleiding Lexicologie zoals opgevat aan de Vrije Universiteit te Amsterdam, voorgesteld.

De lexicon-notie die gehanteerd wordt kan worden weergegeven als: 'een lexicon is een georganiseerde lexicale kennisbank waarover taalgebruikers dienen te beschikken om taal te produceren en te verstaan. Lexicologie houdt zich dan ook, in eerste instantie, bezig met de organisatie van een dergelijke kennisbank Hoe deze organisatie zowel bij het begrijpen als bij het produceren 
van taal een rol speelt wordt aan de hand van enkele voorbeelden verduidelijkt.

In het gedeelte over de opleiding Lexicologie aan de VU wordt ingegaan op de eindtermen van de studie in het algemeen en die van elk studiepad in het bijzonder. Algemeen gesproken staat de notie 'lexicale kennis' (definitie, acquisitie, representatie, derivatie, applicatie en exploitatie van een dergelijke kennis) centraal.

Daarna wordt lexicologie gespecificeerd als

- lexicografie

- terminologie / terminografie

- en computationele lexicologie

en worden, per studiepad, motivatie, doelstelling, eindtermen en beroepsperspectieven kort gekarakteriseerd.

Tenslotte wordt, o.m. door middel van een overzicht van het studieprogramma zelf (waaronder tevens het programma 'Europees Diploma in de Lexicografie'), de samenhang tussen theorie en praktijk, en zodoende het begrip 'universitaire vakopleiding' toegelicht.

Trefwoorden: COMPUTATIONEEL LEXICOLOOG, EUROPEES DIPLOMA IN DE LEXICOGRAFIE, LEXICALE KENNIS, LEXICALE KENNISBANK, LEXICOGRAAF, LEXICOGRAFIE, LEXICOLOGIE, LEXICOLOOG, LEXICON, TERMINOLOGIE, TERMINOLOOG

0. Het getuigt ongetwijfeld van een verregaande en allicht naïef aandoende ijver als men in een tijdschrift als Lexikos aan de lezers probeert uit te leggen wat Lexicologie is: wie draagt nu (wetenschappelijk) water naar de (wetenschappelijke) zee?

Anderzijds is deze houding misschien niet helemaal nutteloos. Het is immers met lexicologie als met taalwetenschap in het algemeen: een definitie lijkt - op het eerste gezicht - makkelijk, overbodig, zelfs tautologisch. Inderdaad, net zoals taalwetenschap kan gedefinieerd worden als de studie van het verschijnsel taal, zo kan lexicologie, naar analogie hiervan, gedefinieerd worden als een lexicon-logie, de logos / studie / leer van het lexicon.

Maar, net zoals je bij taalwetenschap pas écht weet waarover het gaat, als je weet wat met taal bedoeld wordt - en dat hangt, zoals bekend, sterk samen met de theorie die men aankleeft - zo ook wordt lexicologie pas duidelijk als duidelijk is wat onder 'lexicon' moet worden begrepen.

In het eerste gedeelte van dit artikel (1-3) zal ik het dan ook hebben over Lexicologie in het algemeen, alvorens in te gaan op de opleiding Lexicologie, zoals die aan de Vrije Universiteit te Amsterdam wordt opgevat (4-7).

1. Er zijn binnen de taalwetenschap diverse opvattingen over het lexicon. In hun artikel 'Inleiding: de notie 'lexicon" zetten Baayen en Booij de vier voornaamste ervan op een rij (Baayen en Booij 1990). Samengevat en enigszins simplificerend zou men kunnen stellen dat de auteurs de volgende soorten lexicon onderscheiden: 
lexicon-1 = een verzameling bestaande woorden als in een woordenboek, dit is, aldus de auteurs, de pre-linguïstische, naieve opvatting van het lexicon als een losstaande gegevensverzameling;

lexicon-2 = een verzameling idiosyncratische, bestaande, lexicale items (morfemen en morfeemcombinaties); hiermee wordt een linguistisch verantwoord lexicon à la Bloomfield bedoeld waarin "alleen die eigenschappen van woorden [...] moeten worden gespecificeerd die niet voorspelbaar zijn op basis van linguïstische regels" (Baayen en Booij 1990: 2);

lexicon-3 = een verzameling idiosyncratische, bestaande, lexicale items (morfemen en morfeemcombinaties) samen met een verzameling morfologische regels ter vorming van bestaanbare, mogelijke, niet-idiosyncratische morfeemcombinaties; in tegenstelling tot de vorige opvalting wordt de morfologische component, de verzameling woordvormingsregels, deel van het lexicon; het lexicon krijgt mede onder invloed van de generatieve grammatici, een duidelijke dynamische dimensie;

lexicon-4 = een georganiseerde lexicale kennisbank waarover taalgebruikers dienen te beschikken om taal te produceren en te verstaan; hiermee zijn wij bij het mentale lexicon aanbeland waarbij de nadruk valt "op de vragen welke informatie het lexicon in een taalgedragstheorie bevat, hoe deze informatie is gestructureerd, en hoe deze informatie voor de taalgebruiker beschikbaar komt" (Baayen en Booij 1990: 5); het gaat bij lexicon-4 dus niet langer meer alleen om welke items dienen te worden opgenomen, en of er ook regels in staan, nu dienen er ook antwoorden te komen over welke informatie over ieder item gegeven moet worden en welke kennis ieder item vooronderstelt.

Het zal de lezer niet ontgaan zijn dat de laatste definitie (lexicon-4) de meest algemene is en dat de eerste drie, hoe dan ook, elk op hun eigen wijze, een bepaalde vorm van (organisatie van) lexicale kennis en 'know-how' weergeven en dus, in feite, specificaties zijn van vier.

Bij de studie lexicologie aan de Vrije Universiteit zullen wij dan ook van de vierde, meest algemene notie uitgaan, zonder die volledig los te koppelen van de drie eraan voorafgaande. Hoe de samenhang tussen bovengenoemde lexicons begrepen dient te worden zal thans aan de hand van een concreet voorbeeld verder toegelicht worden. 
2. Op voorlichtingsbijeenkomsten van de opleiding of tijdens een inleidend college Lexicologie stel ik, Socrates indachtig, vaak mijn studenten de vragen die zij mij hadden kunnen / willen stellen. Zo b.v. 'wat stel je je in feite bij een lexicon voor?'. Steevast krijg ik dan antwoorden als 'zoiets in de aard van de dikke Van Dale' of, iets minder populair-chauvinistisch, 'een lexicon is een verzameling van alle woorden van een taal zoals die te vinden is in woordenboeken.' Als referentie- en uitgangspunt is dit niet onaardig: lexicologen houden zich inderdaad met woordenboeken bezig, maar dan niet zozeer met wat er letterlijk gedrukt staat in die boekwerken, dan wel met datgene wat er in gedrukt zou kunnen staan, nl. met datgene wat taalgebruikers weten of zouden moeten weten om taal te kunnen produceren en taal te kunnen verstaan. Dat deze kennis een centrale rol speelt bij het bepalen van de betekenis van woorden lijkt evident, maar is daarom nog niet vanzelfsprekend wanneer het gaat om de representatie van woordbetekenis in woordenboeken. Bekijken we even de zinnen (1) en (2):

(1) Ik wou gisteren de trein nemen naar Amsterdam, maar er was staking van het openbaar vervoer.

(2) Ik wou gisteren met de wagen naar Amsterdam komen, maar er was staking van het openbaar vervoer.

De meeste Nederlandstaligen zullen zin (1) als 'normaal' en zin (2) als 'vreemd' ervaren. Als (moeder)taalgebruiker weten we immers o.m. dat er een logischgevolg-relatie bestaat tussen trein en openbaar vervoermiddel (als $X$ een (reizigers)trein is, dan is $X$ een openbaar vervoermiddel) en dat van die relatie gebruik wordt gemaakt in zin (1). Willen we dezelfde relatie leggen in zin (2) dan ontstaat er een 'vreemde' zin, een paradox: een wagen is niet per definitie een openbaar vervoermiddel en toch doen we alsof. Kijken we nu in Van Dale Groot Woordenboek der Nederlandse Taal (12e druk, 1992) onder trein bij betekenis 7 (de betekenis die hier van toepassing is) dan vinden we:

"de spoortreinen in het algemeen, als vervoermiddel, 'het spoor"'

- met als voorbeelden:

"kinderen zijn dol op de trein; de trein rijdt niet meer; je kunt er ook per trein komen".

M.a.w. dit gezaghebbende woordenboek vermeldt niets over het feit dat het bij trein, prototypisch, om een openbaar vervoermiddel gaat, terwijl nu juist dit stukje lexicale kennis elke Nederlandstalige bekend is en door hem / haar gebruikt wordt / kan worden. 
Slaan we nu in hetzelfde woordenboek autobus erop na dan lezen we daarentegen wel iets over de openbaar vervoerfunctie. Een autobus wordt immers gedefinieerd als

"grote, voor personenvervoer ingerichte auto (als openbaar vervoermiddel)".

De moraal van dit verhaal luidt dat van een lexicoloog verwacht kan worden dat hij / zij zich in eerste instantie bezig houdt met de organisatie van woorden en hun betekenis(sen) in een taal. Hoe b.v. trein zich verhoudt tot wagen en tot (auto)bus, hoe die drie in bepaalde opzichten gelijk en in andere verschillend zijn, en hoe van dit alles gebruik zou kunnen worden gemaakt bij het samenstellen van woordenboeken, m.n. bij het consistent definiëren van lexicale items.

3. De organisatie van het lexicon staat niet alleen centraal bij het begrijpen van taal, maar evenzeer bij het produceren ervan. Dit komt met name sterk tot uiting bij het creëren van woorden voor nieuwe begrippen. Daar zich dit vaak bij vaktaal voordoet zal ik het, in wat volgt, voornamelijk over terminologie hebben: de studie van de woordenschat in vaktalen (over het onderscheid algemene taal, vaktaal en subtaal, zie Martin en Ten Pas 1992). Een typisch probleem waarmee een terminoloog geconfronteerd kan worden is b.v. de vraag een term te creëren in het Nederlands voor het Franse woord TGV. Met name bij het zoeken naar benoemingsstrategieën staat de organisatie van het lexicon centraal:

- aangezien we weten dat een TGV een soort trein is,

- en aangezien we weten dat soorten treinen in het Nederlands o.m. als trein-samenstellingen benoemd kunnen worden,

- en aangezien we weten dat de specificator van het soort trein o.m.

- datgene is wat vervoerd wordt:

b.v. reizigerstrein, goederentrein, autotrein, forensentrein, containertrein, veetrein etc.

- het tijdstip is waarop iets / iemand vervoerd wordt: b.v. ochtendtrein, avondtrein, middagtrein, piekuurtrein etc.

- de wijze is waarop iets / iemand vervoerd wordt: b.v. sneltrein, sukkeltrein, stoptrein etc.

- de plaats is naar waar iets / iemand vervoerd wordt: b.v. Lourdestrein, schooltrein, IC-trein etc.

- etc., etc.

kunnen we, op basis van de bovenstaande organisatie / specificatie, het Nederlandse lexicon verder actualiseren, i.c. TGV aan de Nederlandse organisatie aanpassen. 


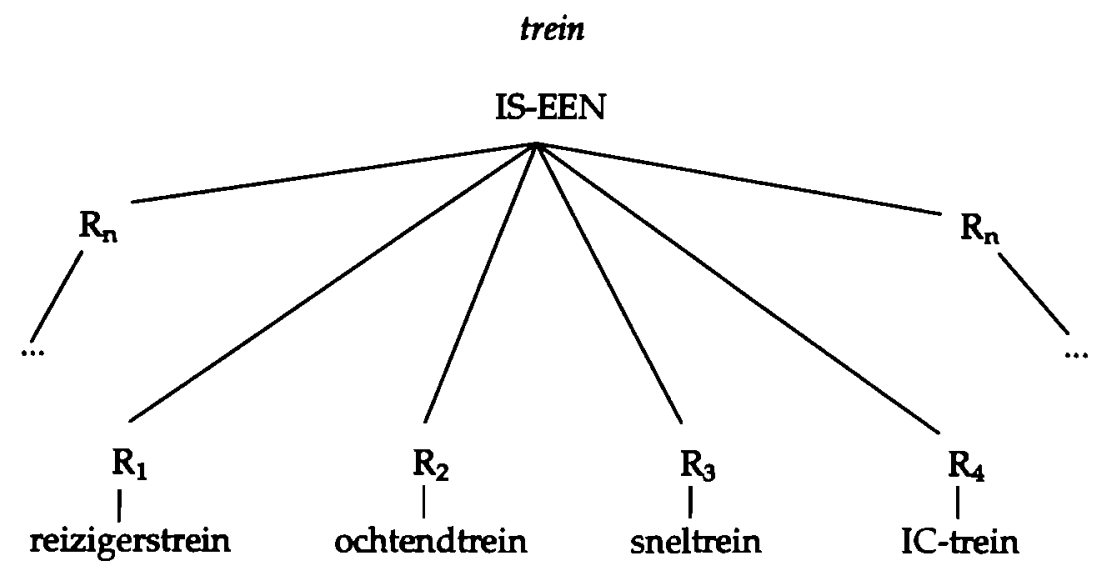

$\mathrm{R}($ elatie $)-1$ = voorwerp

R-2 = tijdstip

$\mathrm{R}-3$ = wijze van voortbewegen

$\mathrm{R}-4=$ (bestemmings)plaats

Als term voor $T G V$ (waarvan het begrip ons bekend is) kunnen we nu, net zoals in het Frans, een R-3 specificator kiezen die op grote snelheid wijst. Aldus ontstonden nieuwvormingen als fitstrein, supersneltrein, SST (supersnelle trein) en HST (hoge snelheidstrein) waarbij de laatste term zich lijkt door te zetten in het Nederlands.

4. In wat voorafgaat heb ik gepoogd duidelijk te maken wat onder lexicon en lexicologie begrepen dient te worden. Hoe staat het nu met de opleiding die deze noties centraal stelt, de opleiding Lexicologie aan de Vrije Universiteit?

In 1986 werd aan de Vrije Unversiteit de studierichting Lexicologie ingesteld om studenten op te leiden tot deskundigen op het gebied van het lexicon, van de woordenschat. Aanleiding tot het oprichten van deze nieuwe studierichting was de toenemende belangstelling binnen de taalkunde voor lexicale vraagstukken enerzijds, de ontwikkelingen binnen de lexicografie en de terminografie anderzijds. O.m. was vastgesteld geworden dat er een aantoonbare behoefte bestond aan lexicologen en terminologen bij:

- de vertaal- en terminologiediensten van de Europese Commissie en het Europese Parlement;

- de vertaal- en informatiediensten van grote, internationaal opererende bedrijven, waaronder DAF-trucks, Fokker, Gist-Brocades, Heineken, Organon, Philips en Shell (speciaal terminologen); 
- de vertaaldiensten van de overheid;

- uitgevers van woordenboeken en naslagwerken (Elsevier, VNU, Van Dale, Wolters-Kluwer etc.).

Aan de andere kant speelde de oprichting van de studierichting in op een aantal recente ontwikkelingen in Nederland, zoals het meerjarenproject van een grote Nederlandse uitgeverij op het gebied van tweetalige woordenboeken en het bestaan van meerdere grote projecten op het gebied van automatisch vertalen in Nederland, waardoor ook de belangstelling voor lexicologische vraagstukken was toegenomen.

Aanvankelijk was Lexicologie een bovenbouwstudie die taalstudenten (Nederlands of een vreemde taal) in de gelegenheid stelde zich te specialiseren in een bepaalde taalkundige richting en af te studeren als lexicoloog of terminoloog. Hierbij werden de volgende begripsomschrijvingen gehanteerd: een lexicoloog bestudeert en beschrijft de woordenschat van een of meer talen, al dan niet in historisch perspectief, terwijl een terminoloog de woordenschat van een bepaald vakgebied beschrijft en uitbreidt, rekening houdend met de structuur van de bestaande woordenschat. Hoewel de studie van de woordenschat als structuur niet aan een bepaalde taal gebonden is, werd ongeveer een derde van de tijd besteed aan voortzetting van de studie van de propedeusetaal.

Vanaf 1991 bestaat Lexicologie als volledige studie, incl. propedeuse. Er is toen tevens een derde afstudeerrichting of studiepad geïntroduceerd (naast die tot lexicoloog / lexicograaf, terminoloog / terminograaf), nl. die tot computationeel lexicoloog (ook wel "lexical knowledge engineer" genoemd). De computationeel lexicoloog houdt zich bezig met de rol van het lexicon in informatiesystemen en de specifieke eisen die hier aan de lexicale beschrijving worden gesteld. Tegelijkertijd zijn de bestaande afstudeerprofielen / studiepaden van lexicoloog en terminoloog aangescherpt. In feite werd Lexicologie van begin af opgevat als een taalkundestudie met een zeer grote nadruk op het lexicon, de lexicale semantiek en de computerverwerking en met een sterke koppeling met een specifieke, duidelijk herkenbare praktijk. Vandaar ook de voorstelling van Lexicologie als een universitaire vakopleiding.

Om dit te illustreren ga ik, in wat volgt, verder in op deze studiepaden. Per studiepad wordt telkens een korte motivatie gegeven naast doelstelling, eindtermen en beroepsperspectieven. Men dient ermee rekening te houden dat studiepaden in feite specialisaties zijn en als zodanig deel uitmaken van de post-propedeuse. Dit betekent dat de student(e) voor het volgen van een van de studiepaden geslaagd dient te zijn voor het eerste studiejaar (de propedeuse) waarbij hij / zij colleges heeft gelopen als Algemene Taalwetenschap, Inleiding Lexicologie, Taalverwerving (inclusief lexicon-1 / lexicon-2 verwerving), Taalstructuur (fonologie, morfologie), Inleiding Computergebruik en Programmeren, Filosofie. Daarnaast zijn er ook heel wat praktische taalbeheersingscolleges Engels (talenpracticum, uitspraak, grammatica, schrijfvaardigheid) gevolgd. 
5. De studierichting Lexicologie wil studenten opleiden tot experten op het gebied van het lexicon. Wat van dergelijke experten verwacht mag worden, wordt in de eindtermen vastgesteld. Weliswaar verschillen deze per studiepad, anderzijds zijn er ook een aantal gemeenschappelijke eindtermen. Eerst volgen dan ook de eindtermen van het algemene deel van de opleiding, daarna wordt specifieke informatie per studiepad gegeven.

\subsection{Gemeenschappelijke eindtermen}

Van een woorddeskundige wordt verwacht dat hij / zij in staat is:

- lexicale kennis te definiëren (d.w.z. te onderscheiden, te specificeren en te situeren t.a.v. algemene kennis, wereldkennis, encyclopedische kennis)

- lexicale kennis te eliciteren (b.v. door informantenbevraging, corpusexploitatie e.d.)

- lexicale kennis te representeren en te structureren

- lexicale kennis met het oog op speciale applicaties / behoeftes / doelgroepen af te leiden

- lexicale kennis m.b.v. beschikbare programmatuur in een databank op te slaan en te exploiteren.

\subsection{Studiepad Lexicografie}

\section{Motivatie}

Hoewel het maken van woordenboeken nog vaak geassocieerd wordt met hand-, om niet te zeggen monnikenwerk, is de lexicografische praktijk de laatste 15 jaar sterk veranderd. Woordenboeken vormen tegenwoordig projecten waaraan door een team van lexicografen wordt gewerkt. De woordbeschrijingen worden eerst in de computer opgeslagen, in zgn. moederbestanden, en kunnen vervolgens voor verschillende woordenboeken worden gebruikt. Het spreekt voor zich dat een dergelijke aanpak alleen mogelijk is als er consistent, volgens bepaalde richtlijnen, wordt gewerkt. Er is dan ook dringend behoefte aan mensen die dergelijke criteria voor de beschrijving van woorden en voor de organisatie van lexicale kennis kunnen opstellen en uitvoeren. Dit studiepad is ingesteld om in deze behoefte te kunnen voorzien (in Europees verband, zie hieronder). 


\section{Doelstelling}

Het studiepad Lexicografie is gegroeid uit een samenwerkingsverband tussen de VU en de universiteiten van Exeter en Lille. Vanuit de Euralex-vereniging (European Association for Lexicography) werd er geconstateerd dat lexicografen nog te vaak 'self-made men' zijn of het met een in-house opleiding moeten stellen. Het doel van de ERASMUS-opleiding Lexicografie is dan ook om beroepslexicografen op te leiden met kennis van tenminste één vreemde taal. Daarom bestaat het programma enerzijds uit gerichte taalkundecolleges om woorden in éen- en meertalig perspectief op systematische wijze te kunnen beschrijven. Anderzijds wordt aandacht besteed aan meer praktische aspecten, zoals de organisatie van woordenboeken met het oog op specifieke doelgroepen en het gebruik van de computer in de lexicografische praktijk. Echte praktijkervaring wordt opgedaan in een stage (in binnen- of buitenland). Ook kan een deel van de keuzeruimte aan één van de andere deelnemende universiteiten worden besteed.

\section{Eindtermen}

- kennis van de basisbegrippen en -methoden op het gebied van de lexicologie / lexicografie

- kennis van lexicaal-semantische theorieën en beschrijvingsmethoden

- kennis van orthografische, fonetische, morfologische, syntactische, semantische, collocationele en pragmatische aspecten van woorden

- kennis van soorten lexicologische produkten en gebruikerstypen

- kennis van programmatuur en gereedschap waarmee lexicale bestanden kunnen worden aangelegd, beheerd en geraadpleegd

- het kunnen toepassen van de hierboven genoemde vormen van kennis (incl. de exploratie van corpora) in de organisatie van lexicale informatie in een woordenboek of woordenbestand en bij het redigeren van woordenboekartikelen of -records.

\section{Beroepsperspectieven}

Lexicografen kunnen terecht bij uitgeverijen van naslagwerken zoals woordenboeken en encyclopedieën, bij software-huizen die zich bezig houden met elektronische woordenboeken en meer in het algemeen in projecten op het gebied van taaltechnologie (waarin vaak wordt samengewerkt door het bedrijfsleven en universiteiten). 


\subsection{Studiepad Computationele Lexicologie}

\section{Motivatie}

Door de snelle ontwikkeling van de technologie is er steeds meer informatie en communicatie mogelijk. De ontwikkeling van geautomatiseerde informatiesystemen staat dan ook centraal in onze moderne samenleving. Informatiesystemen zijn echter zo oud als de mens, zo oud als de taal. Iedereen maakt dus elke dag op grote schaal gebruik van een informatiesysteem, nl. van het sys$t$ em van de natuurlijke taal. M.a.w. wanneer we spreken of schrijven gebrui$k_{\ell}, \alpha$ we taal om informatie over te brengen aan anderen. De laatste tijd is men tot het besef gekomen dat bij deze overdracht het lexicon een zeer belangrijke rol speelt. Net zoals in een relationele database drukken woorden (woordbetekenissen) relaties met andere woorden (woordbetekenissen) uit en op die manier kunnen mensen compact informatie overbrengen, opslaan en begrijpen. Lexicologen houden zich per definitie met de organisatie van het lexicon bezig. Er bestaat dan ook een dringende behoefte aan lexicologen die deze kennis in informatiesystemen weten te integreren.

\section{Doelstelling}

Het doel van dit studiepad binnen de studierichting Lexicologie is de integratie van lexicologische kennis met kennis omtrent automatisering van informatiesystemen. Daarom bestaat het programma enerzijds uit taalkundecolleges met nadruk op lexicale semantiek enerzijds, en uit informaticavakken met nadruk op programmeren en databaseontwerp anderzijds.

\section{Eindtermen}

- kennis van de basisbegrippen en -methoden op het gebied van de lexicologie, de lexicale semantiek en de terminologie

- kennis van orthografische, fonetische, morfologische, syntactische, semantische, collocationele en pragmatische aspecten van woorden

- kennis van programmatuur en gereedschap waarmee lexicale bestanden kunnen worden aangelegd, beheerd en geraadpleegd, inclusief statistische en tekstanalytische pakketten

- kennis van twee programmeertalen, waarvan tenminste eén op een niveau van gevorderden

- het kunnen toepassen van de hierboven genoemde vormen van kennis in de organisatie van een lexicale kennisbank. 


\section{Beroepsperspectieven}

Computationeel lexicologen kunnen terecht bij uitgevers (die zichzelf hoe langer hoe meer als informatieleveranciers ervaren en voorstellen), bij grote bedrijven (b.v. Fokker, IBM, Unilever e.d.), overheidsinstellingen en internationale organisaties waar het ontwerpen, installeren en updaten van informatiesystemen een belangrijke rol speelt, en meer in het algemeen bij taaltechnologie.

\subsection{Studiepad Terminologie en vertalen}

\section{Motivatie}

Door de toenemende internationalisering van het bedrijfsleven, onderwijs en onderzoek en door de eenwording van Europa vindt steeds vaker meertalige communicatie plaats over de meest uiteenlopende onderwerpen. Dit stelt aan de vertaalsector kwantitatieve, maar vooral ook kwalitatieve eisen. Van de vertaler wordt niet alleen een uitstekende beheersing van zijn werktalen verwacht, maar ook dat hij / zij beschikt over specifiek terminologische kennis: welke termen worden door een bepaalde groep experts gebruikt en hoe? Vertalers werken echter vaak onder enorme druk en kunnen zich dan geen tijdrovende speurtocht naar de juiste term permitteren. Met name in die branche is de behoefte aan terminologen en adekwate terminologische hulpmiddelen groot.

\section{Doelstelling}

Het studiepad Terminologie en vertalen heeft tot doel deskundigen af te leveren op het gebied van de woordenschat van specifieke vakgebieden in meerdere talen. Om de voortdurende veranderingen, uitbreidingen in de terminologie van een taal te kunnen beschrijven, is ten eerste inzicht nodig in de conceptuele structuur van vakgebieden en de wijze waarop nieuwe vakconcepten tot stand komen; ten tweede in de wijze waarop deze concepten (kunnen) worden benoemd. Omdat de behoefte aan nieuwe termen vaak voortkomt uit een vertaalsituatie, wordt met name ingegaan op de vertaal- en equivalentie-problematiek en leenprocessen.

\section{Eindtermen}

kennis van de basisbegrippen en -methoden op het gebied van de lexicologie, lexicale semantiek, terminologie en vertaalwetenschap 
- kennis van orthografische, fonetische, morfologische, syntactische, semantische, collocationele en pragmatische aspecten van woorden en hun vertaalbaarheid

- kennis van vaktaal, communicatieve situaties, gebruikerstypen, teksttypen

- kennis van programmatuur en gereedschap waarmee lexicale bestanden kunnen worden aangelegd, beheerd en geraadpleegd

- het kunnen toepassen van de hierboven genoemde vormen van kennis in de organisatie van lexicale informatie in een vakwoordenboek of termenbank.

\section{Beroepsperspectieven}

Terminologen kunnen terecht bij uitgeverijen van vakwoordenboeken en encyclopedieën, op vertaalafdelingen van nationale en supranationale overheidsinstellingen, bij particuliere vertaalbureaus of software-huizen die zich bezig houden met termenbanken of terminologische hulpprogrammatuur. Meer in het algemeen zijn terminologen inzetbaar bij bedrijven / instellingen waar vaktaal wordt verwerkt, b.v. in een documentatiecentrum of bij een educatieve wetenschappelijke uitgeverij.

6. Uit wat voorafgaat moge gebleken zijn dat de studie Lexicologie beoogt een vakopleiding te zijn binnen een universitaire context, d.w.z. dat zij wil opleiden tot de praktijk van resp. lexicograaf, computationeel lexicoloog en terminoloog, en dit d.m.v. een scholing die zowel praktisch georiënteerd als theoretisch gefundeerd is.

Als zodanig is Lexicologie een unieke studie in Nederland: de studierichting is de enige waar men als lexicograaf, als lexicoloog of als terminoloog kan afstuderen. Wel kan men aan de Rijksuniversiteit Leiden binnen een talenrichting de gehele vrije studieruimte ( 1 jaar) vullen met Lexicologie. Het onderscheid met de Leidse variant is vnl. dat de studie Lexicologie aan de VU

- volledig is (inclusief propedeuse)

- zich niet uitsluitend op het Nederlands en op een algemeen lexicon richt (het meertalige lexicon staat centraal en naast het algemene wordt ook het vaktalige lexicon in de studie betrokken)

- een praktijk-stage (in bedrijven) in het programma integreert

- internationalisering nastreeft

Wat dit laatste betreft kan o.m. verwezen worden naar het Europees Diploma in de Lexicografie. Deze opleiding bestaat uit een selectie van colleges uit het doctoraalprogramma en is het meest verwant met het studiepad Lexicografie. 
Afgestudeerden in een moderne vreemde taal aan een Nederlandse of buitenlandse universiteit kunnen dit diploma behalen. De studieduur bedraagt 18 maanden. Dit programma wordt momenteel m.n. door buitenlandse studenten (afkomstig uit Duitsland, Portugal, Griekenland, Zuid-Afrika) gevolgd. Om een idee te geven van de te volgen colleges volgt in appendix een overzicht van het doctoraalprogramma Lexicologie en van de opleiding Europees Diploma in de Lexicografie.

7. Het komt, uiteraard, aan anderen toe om te beoordelen of de hier voorgestelde eindtermen wenselijk en haalbaar zijn, en, zo ja, of ze d.m.v. de voorgestelde opleiding optimaal gerealiseerd kunnen worden. In de loop van de korte geschiedenis van Lexicologie is ons in elk geval duidelijk geworden, dat een nieuw-opgerichte opleiding de kans moet krijgen te groeien, te veranderen, te evolueren. Die kans werd ons, ondanks alle bezuinigings- en reorganisatierondes, in de afgelopen acht jaar gegeven en we zijn de Vrije Universiteit daar dankbaar om.

$\mathrm{Nu}$, acht jaar na de oprichting van de opleiding, zijn ons, meer dan ooit, de consequenties van een bewuste keuze voor een universitaire vakopleiding duidelijk geworden, nl. dat de beste basis voor een goede praktijk nog steeds een goede theorie is, en andersom, dat de beste basis voor een goede theorie, een aan ervaring getoetste praktijk moet zijn. Het nastreven van het juiste evenwicht tussen beide, tussen actie en reflectie, praxis en theorie, blijft voor ons dan ook de grootste, de mooiste uitdaging. Een uitdaging die weliswaar nooit ophoudt maar die tevens uitzicht biedt op verandering, verbetering, evolutie.

\section{Verwijzingen}

Atkins, B.T.S. 1992. Putting lexicography on the professional map. Training needs and qualifications of career lexicographers. Alvar Ezquerra, M. (Ed.). 1992. EURALEX '90 Praceedings: 519-526. Barcelona: Vox Biblograf.

Baayen, R.H. en G.E. Booij. 1990. De notie 'lexicon'. Jaarboek Corpusgebaseerde woordanalyse: 1-17. Amsterdam: Vrije Universiteit, Vakgroep Taalkunde.

Frawley, W. 1988. New Forms of Specialized Dictionaries. International Journal of Lexicography 1: 189-213.

Hartmann, R.R.K 1992. Training in Lexicography. The Exeter ERASMUS Initiative. Alvar Ezquerra, M. (Ed.). 1992. EURALEX '90 Proceedings: 527-553.

Martin, W. 1988. Een kwestie van woorden. Inaugurele rede. Amsterdam: Vrije Universiteit.

Martin, W. en E. ten Pas. 1992. Subtaal en Lexicon. Spektator 20(3/4): 361-375. 


\section{Appendices}

\section{A. Overzicht doctoraalprogramma}

sp = studiepunt; 1 studiepunt correspondeert met een werklast van ongeveer 40 uur.

algemeen verplicht

taalstructuur: syntaxis

$23 \mathrm{sp}$

inleiding databaseprogrammatuur $\quad 1$

inleiding taaltechnologie 2

filosofie (wetenschaps- en taalfilosofie) 3

taalbeheersing Engels

6

taalbeheersing Nederlands

voor Lexicologie verplicht

inleiding terminologie

lexicale semantiek

5

capita selecta

5

database-ontwerp

1

werkcollege lexicologie

3

werkcollege terminologie

per studiepad

Lexicografie

lexicografische oefeningen

pragmatische aspecten

etymologie

stage (min. 3 maanden)

2

scriptie

12

+keuzeruimte

df

Terminologie en vertalen

$46 \mathrm{sp}$

vaktaal

5

vertaalwetenschap

7

computerondersteunde tekstanalyse

4

terminologie en vertalen

5

inleiding Latijn

3

stage (min. 3 maanden)

12

scriptie

10

+ keuzeruimte 
òf

Computationele lexicologie

relationele definitiemodellen

$46 \mathrm{sp}$

logische of cognitieve semantiek

5

statistiek

5

computerondersteunde tekstanalyse

5

vervolg programmeren

4

stage (min. 3 maanden)

5

scriptie

12

+keuzeruimte

10

$33 \mathrm{sp}$

totaal $126 \mathrm{sp}$

\section{B. Het Europees Diploma in de Lexicografie}

Duur: 18 maanden

basiscolleges

inleiding lexicologie

$24 \mathrm{sp}$

werkcollege lexicologie

5

lexicale semantiek

pragmatische aspecten

inleiding databaseprogrammatuur

database-ontwerp

computerondersteunde tekstanalyse

specialisatiecolleges

10-15 sp

b.v.

terminologie (VU)

relationele definitiemodellen (VU)

linguistique et lexicographie (Lille)

learner's dictionaries (Exeter)

stage (min. 3 maanden)

$12 \mathrm{sp}$

scriptie

$10 \mathrm{sp}$ 